\title{
Estado de Derecho Legal y Estado de Derecho Constitucional en el sistema Argentino. Implicancias para la Teoría General del Derecho
}

\section{Legal State of Law and Constitutional State of Law in the Argentine system. Implications for the General Theory of Law}

\section{Leonardo Augusto Schonfeld ${ }^{*}$ Universidad Católica Argentina Paraná, Argentina}

RESUMEN: Los diferentes modelos constitucionales en la historia de la cultura occidental nos dieron dos formas alternativas de entender el rol del poder judicial y la ciencia jurídica. Uno de esos modelos constitucionales es el Estado de Derecho Legal, que nos lleva a comprender que el juez es un esclavo y un custodio de la voluntad del legislador. El sistema del common law, por el contrario, adopta el Estado de Derecho Constitucional, que es un sistema político que ve a los jueces como los guardianes de los más altos principios sociales plasmados en la Constitución y configuran la identidad de esa sociedad. La Teoría General del Derecho debe depender, y debe ser una proyección, de esa configuración. En el caso de Argentina, existe un conflicto entre el modelo constitucional, su historia y las tradiciones académicas.

PALABRAS CLAVE: Estado de Derecho Legal; Estado de Derecho Constitucional; ley y jurisprudencia; rol del juez; control de constitucionalidad.

ABSTRACT: The differents constitutional models in the history of occidental culture, gave us two alternative ways to understand the role of the justice. One of those constitutional models is the Legal State of Law, that bring us the understanding that the judge is a slave and the guard of parliamentary will. The common law system, conversely, adopts the Constitutuional State of Law, wich is a political system that sees the judges as the guards of the highest social principles captured in the Constitution and configures the identity of that society. The General Theory of Law must depend, and should be a projection, of that configuration. In the case of Argentina, there is a conflict between the constitutional model, its history and the academical traditions.

KEYWORD: Legal State of Law; Constitutional State of Law; law and jurisprudence; judge role; constitutionality control.

\section{INTRODUCCIÓN}

La importancia de estudiar y diferenciar los sistemas jurídicos es trascendental. Hay -o debería haber- una íntima relación entre el modelo de Estado que se tiene, el modo de

\footnotetext{
* Abogado, Doctorando en Ciencias Jurídicas en Universidad Católica de Santa Fe, Argentina. Profesor de Introducción al Derecho y de Filosofía del Derecho en Universidad Católica Argentina, Facultad Teresa de Ávila. Correo electrónico: leonardoschonfeld@uca.edu.ar
} 
pensar el Derecho que se sigue de él, y las instituciones jurídicas singulares que terminan de concretar el respectivo modelo. Con más elocuencia se ha dicho que

"es de gran trascendencia saber qué tipo de pensamiento jurídico se impone en un determinado tiempo y en un determinado pueblo. Los distintos pueblos y razas van acompañados de distintos modos de pensar jurídico, y a la supremacía de uno sobre otro puede vincularse un dominio intelectual y con ello político sobre un pueblo. Hay pueblos que existen sin suelo, sin Estado, sin Iglesia, sólo en la 'Ley'; para ellos aparece el modo de pensar normativista como el único razonable, y cualquier otro modo de pensar jurídico, como inconcebible, místico, fantástico o irrisorio. [...], el pensamiento jurídico alemán de la Edad Media era claramente un pensamiento del orden concreto. [...] la recepción que del derecho romano hicieron los juristas alemanes desde el siglo XV lo desplazó y promovió un normativismo abstracto" 1 .

Intento demostrar que hay dos grandes modos de encarar la ciencia jurídica, esto es, se entiende que la ley crea el orden o bien toda ley supone un orden previo. La primera alternativa está anclada en el racionalismo-idealismo, para el cual la realidad nada aporta significativo a la ley y esta es creada a priori, y esto tuvo su completa y más perfecta concreción política en el Estado de Derecho Legal. La segunda, por el contrario, dando primacía a la realidad empírica -sea que se la estudie con una óptica meramente empirista o bien desde un realismo clásico- parte de la base de reconocer la existencia un orden social concreto -enfoque sociológico- y de que la ley no es más que una expresión de ese orden por lo que la ley es manifestación de un orden real y concreto que precisamente permite decir que dicha ley obliga.

El segundo modo de estudiar el orden jurídico y su consecuente modelo científico es el propio del Estado de Derecho Constitucional y es del caso dar cuenta que, reconociendo que los países anglosajones han mantenido con más pureza el Estado de Derecho Constitucional, el modelo continental europeo, hasta el advenimiento del Iluminismo, fue también un modelo de Derecho Constitucional más que Legal.

El Estado de Derecho limita su poder mediante el Derecho, es un modelo de organización política en el que quien dice el Derecho está, a su vez, sometido a él, y recién aparece en el siglo. XVIII en la Europa continental y en el siglo XIII en Inglaterra (esta observación histórica ciertamente puede cuestionarse ${ }^{2}$ ).

\footnotetext{
${ }^{1}$ SCHMitT (1996) p. 8.

${ }^{2}$ Es discutible que la organización política que limite su poder mediante el Derecho sea una construcción de la modernidad y del constitucionalismo moderno. Hay enorme cantidad de ejemplos que demuestran que el poder del Emperador se encontraba limitado por derechos consuetudinarios de toda índole. Solo las monarquías absolutas de los siglos XVII y XVIII pudieron ser algo similar a un poder que, al menos jurídicamente, era ilimitado -aunque de hecho nunca lo fue-. Pero sería un grave error pensar que ninguna monarquía reconoce límites y, mucho más, que el concepto de Imperio puede asociarse a un poder ilimitado.
} 


\section{EL ESTADO DE DERECHO LEGAL. ORIGEN Y CARACTERÍSTICAS DEL SISTEMA JURÍDICO EN TORNO A ÉL}

El origen del Estado de Derecho Legal es el contractualismo liberal que puso en marcha a la Revolución Francesa ${ }^{3}$. La Francia monárquica encontraba su derecho fundamentalmente en la costumbre. Si bien la tarea legisferante se acrecienta con el Estado Moderno asociado a la monarquía absoluta a partir de Luis XIV, esta ingeniería legal nueva estaba orientada a dotar de eficiencia al aparato estatal y, por ello, se dio más que nada en el Derecho Administrativo. Pero el Derecho común seguía siendo fundamentalmente consuetudinario y disperso. Los Parlamentos franceses, propios de cada región o provincia (que hacia el siglo. XVI eran no menos de una treintena) estaban presididos y gobernados por nobles y clérigos. Ellos eran el contrapeso real que encontraba el poder del rey. Cada región contaba con su propio Derecho foral. No debe perderse de vista que

"La unificación del pueblo francés como grupo social, [...], no fue factor decisivo para una temprana uniformidad de legislación. El régimen feudal, que germinó [...] como forma política de características especiales, trajo consigo una mayor dispersión de su derecho. Cada región, cada centro urbano importante, y también, en ocasiones, hasta pequeños villorrios, tuvieron su derecho local; [...] el país fue una extraordinaria conjunción de leyes, cuya diversidad obligó y obliga a reflejarlas en un mapa, donde con la más acentuada gama de colores se señale cuáles eran las normas vigentes para regular las relaciones entre los individuos en los más pequeños lugares del territorio" 4 .

La convocatoria a los Estados Generales era una herramienta que hoy nadie dudaría considerarla una verdadera institución jurídica -en términos de HARIOU- más que una creación legal a la que el rey recurría en casos graves que ameritaran la opinión de todos los estamentos sociales. En el afán de terminar con la dispersión normativa y siendo menester centralizar el poder en un solo gobierno nacional, la Revolución Francesa derogó todo derecho que no provenga de la Asamblea Revolucionaria, y ello por la necesidad política de limitar el poder legisferante que mediante la costumbre tenían las provincias francesas. El nuevo ideario liberal, funcional al poder de la burguesía que acababa de llegar al pleno poderío, no podía permitir que subsistieran otras formas de legislación ${ }^{5}$, siendo entonces la única fuente del Derecho la ley, entendida en su sentido formal, como emanación de un órgano competente sujeto a ciertas condiciones de forma y de procedimiento que aseguren la centralidad del poder de los que participaran de la deliberación. Solo la ley creada mediante esos mecanismos podía ser expresión de la voluntad general. La Revolución

\footnotetext{
${ }^{3}$ Vigo (2016) p. 8.

${ }^{4}$ Guaglianone (1969) p. 285.

5 Más aún, entre la Nación y el Individuo no debía haber ninguna instancia de regulación. Las viejas corporaciones o sindicatos fueron abolidos por la ley Le Chapelier de 1791. Además, es sabido por todos que Francia, desde la Revolución, no admite provincias, siendo un país de constitución Unitaria.
} 
Francesa acabó con el poder del monarca y con el que el pueblo tenía de darse sus propias normas mediante la costumbre ${ }^{6}$.

El racionalismo fue el sustento filosófico que permitió desdeñar el orden jurídico francés y suplantarlo por uno válido a priori, creado ex nihilo por la razón Ilustrada. El Código es la magna obra de aquella, creado por autoridad de la voluntad general, y tomará el lugar de la legislación instaurada durante siglos mediante las costumbres civiles y mercantiles, propias de cada región. El Enciclopedismo mucho incidió en el nacimiento de los códigos, la Enciclopedia era la summa de todo el conocimiento científico de la época y los Códigos son su expresión jurídica, moderna, racional, sistematizada de todo el derecho posible, y sus normas, porque no se extraen de ninguna región en particular ni responden a algún proceso histórico y son fruto de la razón ilustrada, se consideran como una positivización de todo el conocimiento jurídico asimilable por el entendimiento humano, fuera del tiempo y del espacio. Todo derecho válido era el racional y se vertió en los Códigos, el Code era la Enciclopedia Jurídica.

Por mucho que la Revolución pretendiera borrar más de mil años de historia jurídicopolítica dictando una legislación funcional a los intereses de la burguesía, disfrazándolos, obviamente, de una conquista popular, sin duda no podía crear juristas y hombres de derecho de la noche a la mañana y se vio obligada a mantenerlos pero inventando hábilmente un instituto que garantizara un control estricto sobre el accionar de los jueces y así nace la Casación, orientada a controlar la interpretación de la ley que hacían los magistrados del viejo régimen y quienes tienen que obrar ya con las normas del nuevo orden revolucionario, y esto explica por qué el recurso no atañe a cuestiones de hecho y se limita al examen sobre la correcta o incorrecta interpretación de la ley, interpretación que no admite más hermenéutica que la letra estricta de la ley y la voluntad del legislador. El centralismo jamás tuvo tanto ropaje, al punto que hasta resulta poética la frase de CICERÓN "para ser realmente libres, hay que ser esclavos de la ley", y a la cual el Iluminismo se encargó de darle un nuevo sentido, la ley es creación de una razón impersonal, universal y atemporal, no ligada a ninguna voluntad individual ni grupal sino sólo a la abstracta voluntad general.

La Revolución Francesa es la madre de un Estado donde, por consideraciones políticas, filosóficas y científicas, la única fuente del Derecho es la ley emanada de un órgano competente y dictado conforme a ciertos procedimientos, permitiendo distinguir a la ley como expresión de la voluntad general -única válida- de cualquier manifestación popular $y$, verdaderamente, democrática ${ }^{7}$. La influencia de ROUSSEAU sobre todo el pensamiento revolucionario francés y su paso al ideario y normas de la Constitución Argentina lo expone Arturo SAMPAY, quien muestra cómo terminó imponiéndose, pese a ciertas resistencias vernáculas, el Iluminismo francés en nuestra legislación constitucional ${ }^{8}$. Este modo de pensar la constitución política de un Estado, esto es, aquella conformada por la ley, se

\footnotetext{
${ }^{6}$ El Código Napoleón vedaba tajantemente el Derecho consuetudinario y, siguiéndolo, el Código de Vélez Sarsfield también la prohibía expresamente en su art. 17, el que sólo después de la reforma de la ley 17.711 de 1968, incorporó a las costumbres denominadas secundum legem y praeter legem.

${ }^{7}$ Rousseau (2003) p. 60 ilustra esta distinción diciendo que "la voluntad general es siempre recta y tiende siempre a la utilidad pública, pero no resulta que las deliberaciones del pueblo tengan siempre la misma dirección justa".

${ }^{8}$ SAMPAY (1944) p 35.
} 
esparció por toda Europa continental, llegó incluso hasta Rusia, en donde Catalina la Grande hizo suyo todo el ideario Iluminista -que, en su caso y otros, fue un Despotismo Ilustrado-.

La ciencia jurídica quedó en la Europa del siglo XIX signada por esta idea de la primacía de la legalidad, donde las Constituciones, aún las nuevas liberales, no pasaban de ser un programa político, más nunca una fuente de normas jurídicas. En este modelo, creado a partir de la idea de la ley democrática como única fuente del Derecho, el rol del juez se reduce a ser un mero aplicador técnico de los preceptos legales. Lo que comenzó en Francia con la Escuela de la Exégesis continuó luego con el positivismo de Comte y con la posterior creación de una teoría general del Derecho de corte dogmático-legalista.

En Alemania, el pensamiento Historicista parece no haber ganado alguna batalla ${ }^{9}$ y prueba de esto es que todo el pensamiento penal estuvo marcado por el positivismo normativista y la dogmática penal se construyó precisamente en base a la ley y entendida como una delimitación de los alcances de aquellos dogmas. Así, sostiene RotHACKER que la dogmática jurídica en general "es la explicación sistemática de los principios jurídicos que se encuentran en la base de un orden jurídico o de alguna de sus partes" 10 . Aunque puede verse en Alemania que la ciencia jurídica, de todos modos positivista, logra cierta ampliación del horizonte en base a incorporar otros criterios interpretativos -elementos histórico, sistemático, lógico, etc.- y todas las propuestas giran siempre en torno al entendimiento de que la principal fuente del Derecho es la ley y sobre ella deberán centrarse siempre las especulaciones científicas. Por ejemplo, la Jurisprudencia de Conceptos y la obra de von JHERING se centra en la ley, para construir una ciencia de los conceptos legales -dotándolos de la generalidad necesaria para lograr una Teoría General del Derecho-, o sobre el Interés implicado en la ley. En lo que atañe al jurista dogmático, para NINO

"Esa imagen responde a un cuadro cuidadoso que la dogmática fue construyendo, sobre todo en el siglo pasado, con elementos subsistentes de la escuela de la exégesis y sobre todo de la jurisprudencia de conceptos. La idea fundamental es que la dogmática jurídica puede determinar soluciones correctas, que sean unívocas, consistentes y precisas, sin reformular el sistema jurídico a la luz de principios valorativos sino a partir del análisis y combinación de conceptos" $"$.

Eso sí, el normativismo y el apego a la ley concebido como expresión de la voluntad general, que despertó con la Escuela de la Exégesis en torno al Código Napoleón, no fue una teoría precursora aunque lo fue del iuspositivismo. El movimiento exegético, por sus raíces racionalistas, sostenía la idea de un Derecho Natural pero el del Iluminismo

\footnotetext{
${ }^{9}$ Me atrevo a decir que sólo hacia la década del 1930, la obra de Carl Schmitt puso otra vez al historicismo en carrera, frustrada de todos modos por la poco feliz adhesión que dicho filósofo tuviera al nacionalsocialismo, pero que, depurada de dicho contenido político, hubiera podido ser una luz que guiara los caminos de la ciencia jurídica por el camino de las instituciones propias de cada pueblo, de lo que él mismo denominara los "ordenes concretos".

${ }^{10}$ ROTHACKER citado por WeLzel (2005) p. 249.

${ }^{11}$ NINO (2014) p. 103.
} 
racionalista dista mucho del Derecho Natural clásico y el de los exégetas era un conjunto de preceptos descubiertos por la razón a priori, sin considerar la naturaleza empírica del ser humano -que por su adhesión al idealismo kantiano y al racionalismo, nunca podía ser fundamento de alguna norma-. El Derecho Natural del Iluminismo es un constructo puramente racional, además se creía que el juez no tenía ninguna razón para ir en búsqueda de ese derecho natural porque que la mente ilustrada del legislador ya lo había descubierto, sistematizado y plasmado en el código, no hay por tanto excusa con la que el juez de la Francia Revolucionaria pudiera apartarse de la letra estricta de la ley y de la voluntad del legislador.

\section{EL ESTADO DE DERECHO CONSTITUCIONAL}

El Estado de Derecho Constitucional es anterior al de Derecho Legal y sus orígenes datan del siglo XIII, con la presentación de los ingleses de sus peticiones a modo de límite al rey Juan Sin Tierra en 1215. Característico de este modelo de Estado es la idea fundamental de tener el derecho positivo un origen "sociológico" y, lejos de gestarse en el laboratorio de un legislador o parlamentario racional que lo descubre a priori, se busca en las entrañas mismas de la identidad de una comunidad dada. De ahí se sigue, necesariamente, que a distintos usos sociales y complexión social, diferente será el derecho. El juez es la figura que toma y canaliza esa identidad dictando sentencias que van configurando y perfilando los institutos jurídicos, plasmados en eso que el Derecho anglosajón denominó el precedente. Otro aspecto notable de este sistema es la flexibilidad del concepto de derecho, el cual, al no estar ceñido a las decisiones parlamentarias sino a la actividad cotidiana de quienes deben decidir lo justo del caso, permite adaptarse a los cambios sociales los que, menores que los que producen los parlamentos, son más paulatinos y menos pomposos que los cambios de legislación, y lo paradójico es que los países con leyes y constituciones políticas dúctiles son menos propensos a la mutación legal que los con leyes codificadas y cartas rígidas.

La causa de este fenómeno es que para el Estado Legal de Derecho la ley es una expresión esencialmente política - la voluntad general- y sujeta a los vaivenes de ella y en el Estado Constitucional de Derecho este se extrae y configura a partir de cambios sociales profundos, plasmados por los jueces quienes, por concepto, están exentos de las presiones y luchas de partidos políticos. Concebido el Derecho como ley emanada de órganos legislativos está necesariamente asociado a una visión de ella como decisión política signada por la idea de una democracia representativa bajo un sistema partidista, pero acá la ley no deja de ser una herramienta del gobierno y de la ideología de turno y, superada la ficción de la representación democrática de los parlamentos -que pretende que legislar es acto del pueblo-, puede verse que hay distancia entre la ley y las instituciones sociales concretas.

En cambio, el Estado de Derecho Constitucional, que asocia el Derecho a las instituciones políticas solo iluminadas por los grandes y universales principios de la constitución de un país, presenta un Derecho más puro, protagonizado por la sociedad que moldea sus instituciones y su propio Derecho consuetudinario y por el juez como garante de esa identidad según los principios constitucionales. En este modelo de primacía de la Constitución 
"El Estado no se corresponde con la organización política de su población, y ésta de manera fragmentada llega a estructurar regímenes regulatorios de conductas e instituciones y autoridades particularizadas que no se corresponden con la propiamente estatal. [...], resulta visible una crisis profunda y extendida de toda autoridad. La moral social [...], no solo existe sino que llega a tener más eficacia que el derecho"12.

Parafraseando a Carl SCHMITT, podría identificarse al Estado de Derecho Legal con el modo de pensar la ciencia jurídica que él denomina normativismo. Por su parte, parece que lo que el pensador alemán denomina Pensamiento del Orden Concreto ${ }^{13}$ se nos muestra como el más fiel a un modelo de Estado de Derecho Constitucional. Así, "la concepción última que se posea acerca de lo jurídico, de la cual será deducido todo lo que posteriormente venga a ser considerado jurídico, es siempre sólo una: bien una norma (en el sentido de regla o ley), bien una decisión, bien un orden concreto...el derecho racional de los siglos XVII y XVIII... es en parte un normativismo abstracto y en parte un decisionismo" $"$.

Por último, y en abono de la hipótesis inicial de que la tradición jurídica europea no está ligada al Estado de Derecho Legal, precisamente GENTILE pone de manifiesto que "la pretensión, sostenida por la geometría legal, de instaurar un orden, aunque sólo virtual, a partir de un no-orden objetivo, resulta contradictoria desde su raíz; a menos que se atribuya al hombre el poder de crear de la nada, el poder de sacar el ser del no ser" "15 $\mathrm{y}$, es más, como expresa Santi ROMANO, "el derecho no puede ser solamente la norma establecida por la organización social, como a menudo se dice, sino que es la organización social la que entre otras manifestaciones, establece también la norma [...] la objetividad del ordenamiento jurídico [...] no puede circunscribirse y limitarse a las normas jurídicas" $"$.

\section{MODELO CONSTITUCIONAL Y CIENCIA JURÍDICA}

Los Estados de Derecho analizados provienen de modelos culturales distintos y hay que erradicar la falsa idea de que la historia jurídico-cultural europea está vinculada a un modelo legalista pues el Estado de Derecho Legal es una innovación de los siglos XVIII y XIX que, por influjo del imperio napoleónico y del internacionalismo de la Revolución Francesa, fue trasladada a varios países europeos, pero no representa en estos, desde ningún punto de vista, lo que podría llamarse una tradición. Hubo resistencia al modelo jurídico propuesto por la Francia racionalista (Escuela de la Exégesis y Estado de Derecho Legal),

\footnotetext{
${ }^{12}$ Vigo (2016) p. 10.

${ }^{13}$ En Carl ScHMITT encontramos, no obstante, un tercer modo de pensar el Derecho que, me atrevo a decirlo, se vio siempre dejado de lado por la primacía que generalmente se le otorga a uno de los dos modos de pensar el Derecho antes citados: normativismo vs. decisionismo, pero poco se ha reparado sobre la importante puerta de salida que nos presenta Schmitt con su particular Pensamiento del Orden Concreto.

${ }^{14}$ SCHMitT (1996) p. 6. Hago mías las reservas de Arturo SAMPAY respecto del pensamiento de Schmitt, sobre todo en cuanto a que su decisionismo y su devoción a Hobbes parecen llevarlo a avalar regímenes personalistas.

${ }^{15}$ GeNTILE (2008) p. 34.

${ }^{16}$ Santi Romano citado por Gentile (2008) p. 35.
} 
me refiero, puntualmente, al Historicismo jurídico, que rechaza absolutamente la idea de un derecho creado ex nihilo y válido a priori para todo tiempo y lugar. En Alemania, particularmente, se discute este tema y la reacción de la Escuela Histórica contra el legalismo fue tanto vigorosa como perdidosa en esta disputa $\mathrm{y}$, pese a que M. E. MAYER intenta rescatar la idea de que son los fines los que justifican y originan al Derecho y que Julius von KIRSCHMANN "ensalza como verdadero Derecho al Derecho 'natural' tal como vive en el pueblo (es decir, que el concepto del Derecho de la Escuela histórica se había convertido en Derecho natural en 1848)" "17, el influjo del historicismo fue muy menor de lo esperado.

Con todo, el modelo legalista se terminó imponiendo, viéndose el Derecho, con toda claridad, bajo una concepción que podría denominarse dogmático-legalista, y que se nutrió tanto de la filosofía idealista kantiana (sin grandes diferencias metafísicas y gnoseológicas con el racionalismo heredado del Iluminismo) como del empirismo.

Por la vertiente del empirismo, aparece la concepción comteana ${ }^{18}$ y humeana acerca de la ciencia: sólo el fenómeno empírico puede ser objeto de saber científico. Llegó el momento, pues, de tratar al derecho con ese método y se comenzó a ver a la ley como un hecho y aquella es un factum, verificable empíricamente con el solo recurso de abrir un digesto y verla ahí, escrita, puesta. Posteriormente KELSEN dirá que la norma no es otra cosa que el hecho de que alguien quiere que otro haga algo ${ }^{19}$. La ley es voluntad y esta, en tanto querer, es un hecho. El positivismo empirista determinó, en el ámbito del Derecho penal, la creación de la ciencia jurídica como dogmática, esto es, de explicación axiomática del precepto legal, y la acción humana estudiada por el Derecho punitivo fue entendida en clave causal-empirista como una modificación perceptible del mundo exterior y se redujo la ciencia criminal al estudio de las causas del delito y de su efecto empírico, o sea, la pena. Justamente, "[...] en 1893, [...] Franz Von Liszt dejaba en pie la cuestión de si la dogmática del Derecho penal era o no una ciencia; seis años más tarde, empero, verá el cometido de la dogmática tan sólo en la formación pedagógica de los criminalistas prácticos, mientras que la labor científica del criminalista consiste sólo, para él, en la indagación de causal del delito y de los efectos de la pena"20.

En el siglo XX aparece la Corriente Hermenéutica como un intento de superar el modelo dogmático y de aplicación mecanicista de la ley y logró solo atacar esto último pero no al concepto de lo jurídico mismo porque, aún reconociendo la necesidad de interpretar toda norma jurídica, la mencionada tendencia seguía entendiendo al Derecho en sentido normativo, siendo entonces la ley siempre una parte esencial del círculo hermenéutico.

\footnotetext{
${ }^{17}$ WELZEL (2005) p. 250.

${ }^{18}$ Manifiesta COMTE (1875) p. 71 que "el espíritu humano, por su naturaleza, emplea sucesivamente en cada una de sus investigaciones tres métodos de filosofar, cuyo carácter es esencialmente diferente $i$ aún radicalmente opuesto: [...] el método teolójico, [...] el [...] metafísico i [...] el positivo. De alii provienen tres especies de filosofías, o de sistemas jenerales de concepciones sobre el conjunto de los fenómenos, que se escluyen mutuamente: la primera es el punto de partida necesario de la intelijencia humana; la tercera, su estado fijo i definitivo; la segunda está únicamente destinada a servir de transición".

${ }^{19}$ KELSEN (1960) p. 36.

${ }^{20}$ WeLZEL (2005) p. 251
} 
Por el contrario, en el ámbito del common law la norma jurídica ocupa un lugar mucho menos importante en la elaboración científica. Haciendo parte esencial de su pensamiento la idea desarrollada por JELLINEK sobre el valor normativo de lo fáctico, para Alf ROSS el único derecho real es el vigente y este es el que efectivamente es obedecido y aplicado por los jueces y operadores del sistema jurídico ${ }^{21}$, y HART, por mucho que su teoría del Derecho esté ligado al concepto de norma -sustituido en su discurso por el término reglafunda su idea del Derecho en la Regla de Reconocimiento, que es aquella que permite saber acerca de la pertenencia o no de una regla al sistema, pero ella misma no está creada por autoridad u órgano competente sino que es el conjunto de criterios que de hecho usan los operadores del sistema, o sea, se trata de hechos, por lo mismo, las reglas pertenecerán al sistema y serán válidas si pueden pasar por el tamiz de criterios que efectivamente componen la conciencia jurídica de los señalados operadores. En opinión de HART, lo mismo Ross, la jurisprudencia precede a la ley en tanto fuentes del Derecho, "los criterios [...] dados pueden, [...], asumir una o más formas [...]: entre ellas se encuentran las referencias a un texto revestido de autoridad; a una sanción legislativa; a la práctica consuetudinaria; a las declaraciones generales de personas especificadas; o a decisiones judiciales pasadas, dictadas en casos particulares",2 y, aunque "el common law está subordinado a las leyes",23, las reglas "[...] no deben su status de derecho, por precario que este sea, a un ejercicio 'tácito' de potestad legislativa, sino a la aceptación de una regla de reconocimiento que les acuerda ese lugar independiente, aunque subordinado"24.

\section{LA ESQUIZOFRENIA JURÍDICA COMO RASGO DISTINTIVO DE LA ARGENTINA}

En Argentina conviven los dos modos de pensar el Derecho y en el orden constitucional es fuente que le sirve de guía hermenéutica, siendo una de sus principales nutrientes, la Carta de los Estados Unidos de Norteamérica, de la que, solo por ejemplificar, se ha heredado el instituto jurídico del Juicio por Jurados a la organización judicial -fundamentalmente a la competencia que le cabe a la Corte Suprema de Justicia de la Nación-, y hay obviamente también otros importantes institutos en la norma fundamental foránea, tales como la libertad religiosa, la concepción liberal de los derechos de primera generación, el federalismo, el republicanismo, el presidencialismo, y sin perjuicio de que los mismos no son propios del sistema de los Estados Unidos sino que compartidos en todo el constitucionalismo de los siglos XVIII y XIX.

Hay un fuerte vínculo con la madre patria, España, que deja su huella en la legislación argentina, de hecho el federalismo, si bien es denotativo del modelo norteamericano, hunde sus raíces en la vieja España foral la que, en América Latina, se expresó en los virreinatos, las intendencias y los cabildos. El influjo español se ve también en el Derecho procesal, el que, de carácter inquisitivo, se adoptó desde un comienzo para los juicios penales y mantuvo hasta la década del 1980 en casi todas las provincias para dar paso a un sistema mixto. En el Derecho procesal recursivo aun persiste la idea monárquica de ejercerse la

\footnotetext{
${ }^{21}$ Alf Ross citado por VIGO (2006) p. 54.

${ }^{22}$ HART (1968) p. 125.

${ }^{23}$ HART (1968) p. 126.

${ }^{24}$ Ibíd.
} 
jurisdicción por delegación y que en caso de apelación se devuelve al superior -efecto devolutivo de toda apelación-. El Derecho Administrativo, por su organización jerárquica, es el que mayor influencia hispánico-borbónica tiene.

En cuanto al origen de nuestra constitución política de 1853, dice SAMPAY que

"La filosofía del Iluminismo infunde el espíritu a la Constitución de 1853; claro está, morigera dos sus principios por fuerzas morales relapsas del tradicionalismo hispano y que [...] encontraron un clima favorable en el sentimentalismo teísta del Romanticismo [...]. La generación romántica, que realizó la ordenación jurídica del país, y especialmente Alberdi, coautor decisivo de la Constitución de 1853, concibieron una técnica historicista para el ideal iluminista de la Revolución de Mayo. De aquí viene el condicionamiento cultural de nuestra Constitución, con una marcada tendencia al economismo burgués, que fue lo típico de la fase conclusiva de la Ilustración" $"$.

Encontrar distintas y contradictorias visiones del Derecho en el nacimiento de la Constitución argentina es patente con Juan Bautista ALBERDI al sostener que caricaturizando al país que él mismo ayudó a construir según afirma RosA-

"En ese medio corrompido por Tartufo y los suyos, Luz del Día encuentra a Don Quijote más loco que nunca, 'qué ha hecho de la libertad su Dulcinea. En España se creía un héroe, aquí se cree un Dios. ¿Que la libertad sea!, dice aquí como el que dijo iSea la Luz!, y el loco quedó creído que la libertad ha nacido y es un hecho porque existe su decreto escrito... Decreta hombre libres, forma municipales, hace legisladores y electores por la mera virtud de sus decretos escritos... Suprime la historia del país y la complexión o constitución social que un país debe a su historia secular, por un decreto en el cual ordena que lo que ha sucedido no sea lo que ha sucedido, sino lo que ha dejado de suceder... Decreta para su país de constitución o complexión hispanoamericana, la constitución o complexión de Norte América, que es la obra natural de los hechos que forman la historia angloamericana... No hay quien disuada a Don Quijote que un decreto escrito no es, por sí solo, una institución, es decir, un hecho real, por el hecho cierto de estar escrito'. Con los carneros de su estancia que por decreto ha hecho nacer hombres libres a la sajona, 'suprimiendo a quienes se empeñen en nacer ilegalmente en forma de carneros' hace una república constitucional de vida efímera" 26.

Dicha situación se repite claramente en el Derecho Común, en las normas de los artículos 16 y 17 del Código Civil Argentino de 1871, que, en cuanto a las fuentes del Derecho, acoge una patente impronta exegética. El art. 16, disponiendo "Si una cuestión civil no puede resolverse, ni por las palabras, ni por el espíritu de la ley, se atenderá a los principios de leyes análogas; y si aún la cuestión fuere dudosa, se resolverá por los principios generales del derecho, teniendo en consideración las circunstancias del caso",

\footnotetext{
${ }^{25}$ SAMPAY (1944) pp. 7-8.

${ }^{26}$ Juan Bautista ALBERDI citado por RosA (1973) p. 174.
} 
hizo suyo los dos únicos criterios interpretativos admitidos por la Escuela de la Exégesis, esto es, el literal y la voluntad del legislador. El art. 17 recortó a la costumbre su calidad de fuente del Derecho al establecer que "Los usos y costumbres no pueden crear derechos sino cuando las leyes se refieran a ellos o en situaciones no regladas legalmente". O sea, el mentado Código Civil está, en cuanto a la forma de encarar los problemas generales del rol del juez y de las fuentes del Derecho, imbuido de un espíritu legalista de corte francés, dentro de un modelo de Estado de Derecho Constitucional.

Aunque es enorme la influencia del modelo Iluminista y Racionalista en los orígenes de la Constitución de Argentina, la Corte Suprema de Justicia de la Nación dictó un fallo relevante para interpretar cuál es el sistema al decir que

"Alberdi y los constituyentes de 1853 optaron por el modelo norteamericano, originariamente opuesto por completo al europeo, su antípoda institucional. Los constituyentes norteamericanos, al proyectar el modelo que luego tomaría la Constitución Nacional, no desconfiaban de los jueces, sino del poder central -federal- que creaban. Temían generar un monstruo que lesionase o suprimiese el principio federal. Los derechos consagrados en la Constitución de los Estados Unidos, en su origen, no limitaban las leyes de los estados, sino sólo las leyes federales. Los norteamericanos se independizaban de la Corona, pero no querían instituir un poder central -federal-que en definitiva viniese a ejercer un poder arbitrario análogo. Por ello, dieron a todos los jueces la facultad de controlar la constitucionalidad de las leyes y, en última instancia, a su Corte Suprema. El Poder Judicial norteamericano no era jerarquizado ni corporativo, sino horizontal, con el control difuso de constitucionalidad; el único elemento de verticalidad fue el stare decisis. En lugar de encargar a los legisladores el control de los jueces -como los franceses-, los norteamericanos pusieron a los jueces a controlar a los legisladores" 27 .

En resumen, existe en la cultura jurídica argentina una situación que, por razones históricas, pedagógicas y normativas, permite afirmar que el modelo es el de un Estado de Derecho Legal (Códigos Civil, Comercial, Penal, Procesales ${ }^{28}$ ) y el de un Estado de Derecho Constitucional, y entiendo que este escenario debe leerse correctamente acorde la evolución de los acontecimientos históricos que fueron generando un cambio de rumbo hacia un modelo de Estado de Derecho Constitucional.

\section{INTERPRETACIÓN Y APLICACIÓN DEL DERECHO EN LOS MODELOS CONSTITUCIONALES ANALIZADOS}

\footnotetext{
${ }^{27}$ Corte Suprema de Justicia de la Nación, Casal, Matías Eugenio y otro s/ robo simple en grado de tentativa (2005, Causa $\mathrm{N}^{\circ} 1681$ ), considerando 11.

${ }^{28}$ En el Derecho Procesal Penal, sin poder negarse el avance que significó la incorporación de la oralidad y los juicios acusatorios y, en algunas provincias, el Juicio por Jurados -según exigiría el modelo constitucional y procesal anglosajón-, todavía las investigaciones penales preparatorias (que suplantaron a la instrucción) son una instrucción oralizada y se está lejos aún imponerse un verdadero proceso penal contradictorio y acusatorio puro.
} 
Los modelos constitucionales examinados dan lugar a dos visiones muy distintas respecto del objeto de la ciencia jurídica y en cuanto a la interpretación y aplicación del Derecho.

\section{Afirma SANTIAGO que}

"existen dos visiones alternativas y en parte complementarias de la realidad jurídica. El Derecho puede ser visto y definido [...] como un conjunto de normas que regulan la conducta humana y la vida social. Podemos denominar a esta concepción como la visión sistemática del Derecho [...]. Alternativamente a ella, podremos considerar inicialmente a la realidad jurídica como el conjunto de problemas humanos, en sentido muy amplio, que deben ser resueltos con justicia para lograr la coexistencia armónica de las personas y grupos sociales que conviven en una comunidad política. Ésta es la visión problemática del Derecho, donde el foco principal de atención del análisis jurídico se sitúa no ya en las normas, sino en la resolución justa de los diversos problemas reales y concretos que plantea la convivencia humana"29.

Importando obviamente para SANTIAGO los modos de entender al Derecho formas distintas de concebir la investigación jurídica, la enseñanza de aquel y los roles de los operadores jurídicos, en mi opinión el modelo de ciencia jurídica del Estado de Derecho Constitucional es muy semejante -o el mismo- que el que se derivaría de lo que el autor citado pone como un modo originario y antiguo de comprender el Derecho, ligado al Derecho Romano y las fundamentaciones aristotélicas, y concluyo que el modelo de ciencia jurídica del Estado de Derecho Constitucional se nutre de una concepción aporética del Derecho, en contraposición al sistematicismo legalista y racionalista propio del Estado de Derecho Legal.

El modelo del Estado Legal de Derecho ha dado lugar a lo que se denominó la teoría del silogismo judicial y el del Estado Constitucional de Derecho ha propiciado un análisis previo a la aplicación de la ley o, al menos, ha permitido un acomodamiento de los contenidos de la norma según necesidades éticas y constitucionales.

En el pensamiento de corte continental europeo, la imagen del juez de MONTESQUIEU como la boca inanimada de la ley, y que pervivió en los juristas positivistas de todo el siglo XIX y primera mitad del XX, evolucionó a la par que el legalismo racionalista francés fue mutando hacia el positivismo. El estudio de la ciencia jurídica positivista estaba ligado, en sus orígenes, al mandato político que significaba el apego a la ley y solo se amplió el horizonte respecto de los criterios interpretativos pero no tanto en cuanto al objeto de la interpretación, que seguía siendo la norma legal, y por ello la teoría del silogismo no es más que una serie de tesis básicas que muestran el sentido legalista con que se aplicaba el Derecho, esto es, solo se aplican las normas legales, la Constitución del Estado se reduce a un mero programa político, la norma se concibe como algo dado al intérprete y funciona como premisa mayor del silogismo y es -cuando la hay- la única dimensión de la interpretación, los hechos se presentan como algo bruto y en sentido naturalístico, y, las reglas lógicas de la inferencia son las únicas herramientas usada por el juez.

\footnotetext{
${ }^{29}$ SANTiago (2010) p. 106.
} 
La reacción contra el modelo de aplicación mecanicista de la ley o silogismo judicial que encarnó la corriente Hermenéutica parecería que llevaría las cosas hacia el horizonte opuesto pero Arthur KAUFMANN, uno de los más importantes exponentes de la antedicha tendencia,

"también ha reconocido el papel de las normas y ha marcado distancias con la Escuela de Derecho Libre. Aunque considere que el Derecho sólo existe de manera concreta, subraya que esa existencia no puede tener lugar sin una norma previa: esta es la condición necesaria, aunque insuficiente, para el Derecho concreto. En consecuencia, rechaza la denominada ética de situación existencialista, porque rechazar las reglas en favor del Derecho que portaría en sí misma cada situación resulta imposible; la juridicidad de un estado de cosas concreto sólo es comprensible al presuponer una medida general de lo justo", 30 .

El cambio de paradigma hacia un Estado de Derecho Constitucional "opera encomendando a jueces el controlar la constitucionalidad de los actos y normas generados por autoridades o particulares, lo que implica la superación del 'paradigma paleopositivista del estado legislativo de derecho' (Ferrajoli), un nuevo desafio al positivismo (Prieto Sanchis) $[\ldots]^{, 31}$.

Ahora bien, terminada la Segunda Guerra Mundial, la ciencia jurídica viene dando un giro cada vez más claro hacia un modo de aplicar el Derecho más coherente con el de un Estado de Derecho Constitucional ${ }^{32}$. Es insoslayable referir la aparición, a partir de la segunda mitad del siglo XX, de las denominadas Teorías de la Argumentación pues ellas, pese a sus diferencias y críticas que puede hacérseles, tienen el mérito de sustraer al juez de una actitud de sumisión al texto legal para ir en búsqueda de la racionalidad, lo que hace, en definitiva, que en el modelo del Estado de Derecho Constitucional el magistrado tenga un rol preponderantemente garantístico respecto de la racionalidad de las decisiones, entendiendo como racional lo opuesto a lo arbitrario y esto sinónimo de inconstitucional.

\section{Dice OLLERO,}

"[...]. [...] hoy día la teoría jurídica, consciente de la limitación de la ley, pone de manifiesto el perfil jurisprudencial del derecho (...). La tarea jurídica consiste, pues, fundamentalmente en una labor de determinación. Esto quiere decir que el derecho no es una estática norma abstracta, sino primordialmente acto: un ocurrir real entre los hombres, mientras que la ley -no por imperfección ocasional, sino por su misma esencia- es sólo posibilidad de derecho", 33 .

\footnotetext{
${ }^{30}$ RODRÍGUEZ PUERTO (2010) p. 325.

${ }^{31}$ VIGO (2003) p. 9.

${ }^{32}$ VIGO (2016) p. 8.

${ }^{33}$ Andrés OLLERO citado por Vigo (2003) p. 216.
} 
La nueva presencia de las teorías de la argumentación y la creciente influencia que en el campo de la Filosofía del Derecho tiene el neo kantiano Robert ALEXY lleva a una vuelta a las fuentes, y la argumentación jurídica, pilar del Estado de Derecho Constitucional, exige a los juristas desempolvar libros olvidados por más de ciento cincuenta años, y si aquel es un modelo de principios constitucionales universales, aplicables según su peso específico en el caso, y tales principios son -en términos de ALEXY- mandatos de optimización ${ }^{34}$ que no dan una conducta concreta a realizar sino un motivo o razón para discurrir en determinado sentido, es evidente que la Tópica, la Retórica, la Dialéctica y la Lógica han de ser materias de primer orden.

En otros términos, esa evolución en el campo de la ciencia jurídica y la filosofía jurídica no se ha volcado aún a la enseñanza del Derecho y los cánones legalistas siguen estando absolutamente vigentes en nuestras universidades. Así,

“[...] Básicamente se enseña el derecho positivo, los mecanismos legales, algunas líneas jurisprudenciales, y las principales interpretaciones doctrinarias sobre las soluciones legales [...] En las facultades de derecho se enseña el derecho positivo [legal], se explican las soluciones de la ley y, en el mejor de los casos, se las confronta con la realidad a través del análisis de algunos casos de jurisprudencia",35.

Y en efecto, "pocos cambios se advierten en la formación del grado en nuestras Facultades de Derecho las que casi inalterablemente siguen repitiendo los esquemas trazados por aquellas decimonónicas universidades francesas de inspiración napoleónica, que fueron funcionales al Estado que se había creado bajo los influjos de la filosofía iluminista y liberal de los siglos XVII y XVIII" ${ }^{36}$.En el mismo sentido se ha afirmado que el modelo legalista "es uno de los mitos más persistentes de la ciencia jurídica de los últimos dos siglos" ${ }^{37}$ y que "si bien ha sido ya superado conceptualmente por la doctrina iusfilosófica y dejado de lado por la práctica de los tribunales, especialmente de aquellos de más destacada actuación, sique estando presente de modo preponderante en la enseñanza jurídica y en la mentalidad de muchos abogados, jueces y del público en general"38.

Esta situación de la ciencia jurídica, ligada aún al positivismo legalista y, por ende, a una concepción de Estado de Derecho Legal, realizada por profesores carentes de formación iusfilosófica ha sido ya denunciada mucho tiempo atrás y dado que persiste sigue siendo necesario reafirmarla. La confirmación de lo que en este trabajo se entiende como un Estado de Derecho Constitucional implica rescatar el Derecho como respuesta a problemas y en contra de aquella tradición donde la dogmática y la enseñanza del derecho en el ámbito del derecho continental se restringe a la descripción y memorización del sistema normativo.

\footnotetext{
${ }^{34}$ ALEXY (2012) p. 67.

${ }^{35}$ MAZZINGHI (2005) pp. 255- 256.

${ }^{36}$ Vigo (2016) p. 9.

${ }^{37}$ Luis PRIETO SANChís citado por SANTIAGo (2010) p. 109.

${ }^{38}$ Santiago (2010) p. 109.
} 


\section{CONCLUSIONES}

El dilema aquí planteado es el que sustenta Carl SCHMITT al afirmar que hay dos posibles respuestas a la realidad jurídica de todos los tiempos, esto es, la ley es causa eficiente del orden, creadora de un orden social, o bien la ley es efecto y consecuencia de un orden previo a partir del cual precisamente puede decirse que posee autoridad para obligar, y sobre tal se postula en el Estado de Derecho Legal, con el Iluminismo racionalista como fundamento filosófico-político (y que luego el neokantismo reafirmó y llevó al plano científico-jurídico), que la ley es causa y el orden su consecuencia ${ }^{39}$ y en el Estado de Derecho Constitucional que toda ley, incluso las Constituciones, no es más que una expresión de la elección política que un pueblo ha hecho respecto de los valores y principios que entiende fundamentales.

Como se ve, conviven en la cultura jurídica argentina las resistencias historicistas que el mismo ALBERDI no pudo desconocer ${ }^{40}$ y el Iluminismo como modelo jurídico-político casi expresamente adoptado por el texto constitucional. Lo que ocurrió es que el ideal iluminista de la Constitución escrita y codificada no debía demorarse más y, por ello, fue necesario que los principales exponentes del pensamiento unitario y liberal hicieran ciertas concesiones al federalismo que encontraba adeptos mayoritarios por todas partes en nuestro país. Nace así, desde el origen, una Constitución Argentina fruto de renuncias políticas pero que nunca saldó los modos antitéticos de pensar lo político y jurídico.

Las grandes diferencias no resultan solo de la dicotomía Estado de Derecho Legal vs. Estado de Derecho Constitucional sino que son mucho más profundas, por ejemplo, si la ley es causa o consecuencia del orden político-social, el centralismo unitario vs. la descentralización federal, la organización jerárquica del aparato judicial siguiendo el modelo de justicia por delegación o bien una organización horizontal en el que los tribunales superiores solo tengan por objeto terminar una contienda y garantizar la constitucionalidad de toda decisión. Estas, entre otras, son diferencias que, según se haga hincapié en uno de los extremos, irán moldeando teorías jurídicas opuestas.

Opino que la vertiente historicista no tuvo casi adeptos en el modelo de enseñanza del Derecho pero en la medida en que los resabios legalistas y dogmáticos se van dejando atrás parece hacerse presente cada vez con más fuerza la idea opuesta, esto es, el modelo heredado por nuestro país fue el del Estado de Derecho Constitucional y esto no solo por ser la Constitución Norteamericana fuente de la Carta de Argentina de 1853 sino porque la tradición europea imperial también fue antilegalista y federal, opacada sí por el triunfo y expansión de la Revolución Francesa.

El avance en la comprensión de dicha idea debe, por lo mismo, compelernos a reelaborar los planes de estudios de nuestras Universidades y a desterrar el modelo de aplicación

\footnotetext{
${ }^{39}$ En la historia argentina este dilema Juan Manuel de Rosas lo trató abiertamente y expresó en la famosa Carta de la Hacienda de Figueroa que le envió a Facundo Quiroga y que este tuvo consigo al ser muerto en Barranca Yaco (la misiva aún se conserva, ensangrentada, en el Archivo General de la Nación).

${ }^{40}$ Para mejor entendimiento de este tema vid. por todos CHÁveZ (1977).
} 
mecanicista de la ley siendo ya la argumentación jurídica, iluminada por los principios constitucionales, la principal herramienta de aplicación del Derecho.

\section{BIBLIOGRAFÍA CITADA}

ALEXY, Robert (2012): Teoría de los Derechos Fundamentales (2 $2^{\mathrm{a}}$ ed, Madrid, Centro de Estudios Políticos y Constitucionales).

CHÁveZ, Fermín (1977): Historicismo e Iluminismo en la Cultura Argentina: Juan Cuello, Rosas, Vico, Herder, Alberdi, Castañeda, Castellani, Nimio de Anquín (Buenos Aires, Editorial del País).

ComTe, Augusto (1875): Principios de Filosofía Positiva (Trad. Jorje Lagarrigue, Santiago de Chile, Imprenta de la Librería del Mercurio).

Gentile, Francesco (2008): Ordenamiento Jurídico. Entre Virtualidad y Realidad. ¿control social y/o comunicación interpesonal? (Trad. María de Todos los Santos de Lezica, $2^{a}$ ed., Buenos Aires, Instituto de Estudios Filosóficos Santo Tomás de Aquino).

Guaglianone, Aquiles Horacio (1969): "Napoleón y su Código Civil" (Conferencia realizada el 23 de octubre de 1963 en la sede del Departamento de Historia de la Facultad de Filosofía y Letras de la Universidad de Buenos Aires), pp. 283-205. Disponible en: http://www.derecho.uba.ar/publicaciones/lye/revistas/4041/napoleon-y-su-codigo-civil.pdf, fecha de consulta: 20 de marzo de 2019.

Hart, Herbert L. A. (1968): El Concepto de Derecho (Trad. Genaro Carrió, $2^{\text {a }}$ ed., Buenos Aires, Abeledo-Perrot).

Kelsen, Hans (1960): Teoría Pura del Derecho (Buenos Aires, Eudeba).

MAZZINGHI, Jorge (2005): "La Enseñanza del Derecho. ¿Transmisión de Conocimientos Jurídicos o Formación de Abogados?”, en Vv.AA. La Codificación: Raíces y prospectivas III. ¿Qué derecho, qué códigos, qué enseñanza? (Buenos Aires, Universitas), pp. 255-259.

Nino, Carlos Santiago (2014): Derecho, Moral y Política: Una Revisión de la Teoría General del Derecho (Buenos Aires: Siglo Veintiuno Editores).

Rodríguez PuerTo, Manuel Jesús (2010): "Métodos de Interpretación, hermenéutica y derecho natural", Díkaion, Año 24, Vol. 19, № 2, pp. 319-347.

RosA, José María (1973): Historia Argentina. T. VIII (Buenos Aires, Editorial Oriente).

Rousseau, Jean Jacques (2003): El Contrato Social o Principios de Derecho Político (Trad. Leticia Halperín Donghi, Buenos Aires, Editorial La Página). 
TAMAYO y SALMORÁN, Rolando (2004): Los publicistas medievales y la formación de la tradición política de occidente: estudio histórico sobre la recepción de la ciencia jurídica y su impacto en las ideas políticas (México D.F., Instituto de Investigaciones Jurídicas Universidad Autónoma de México).

SAMPAY, Arturo (1944): La Filosofía del Iluminismo y la Constitución Argentina de 1853 (Buenos Aires, Depalma).

SANTIAGO, Alfonso (2010): En las fronteras entre el Derecho Constitucional y la Filosofía del Derecho. Consideraciones iusfilosóficas acerca de algunos temas constitucionales (Buenos Aires, Marcial Pons).

(2017): Estudios de Derecho Constitucional. Aportes para una visión Solidarista del Derecho Constitucional (Buenos Aires, Marcial Pons).

SCHMITT, Carl (1996): Sobre Los Tres Modos de Pensar la Ciencia Jurídica (Madrid, Tecnos).

VIGO, Rodolfo Luis (2003): De la Ley al Derecho (México D.F., Editorial Porrúa).

, (2006): Perspectivas Iusfilosóficas Contemporáneas: Ross, Hart, Bobbio, Dworkin, Villey, Alexy, Finnis (2 $2^{\mathrm{a}}$ ed., Buenos Aires, Abeledo Perrot).

, (2016): El Estado de Derecho Constitucional y Democrático (Quito, Corporación de Estudios y Publicaciones).

Welzel, Hans (2005): Introducción a la Filosofía Del Derecho. Derecho Natural y Justicia Material (Trad. Felipe González Vicén, Montevideo - Buenos Aires, B de $f)$.

\section{JURISPRUDENCIA CITADA}

Corte Suprema de Justicia de la Nación, Contra Casal, Matías Eugenio y otro (2005), Causa $\mathrm{N}^{\circ} 1681$, considerando 11. 